\title{
ANALISIS SQUARE CUP DEEP DRAWING
}

\author{
Uud Achmad Imadudin, Marwan Effendy \\ Teknik Mesin Universitas Muhammadiyah Surakarta \\ J1. A.Yani Tromol Pos I Pabelan, Kartosura \\ email : effendy@ums.ac.id
}

\begin{abstract}
The applications of sheet metal forming is very important in the automotive industries since most of the car components are produced by press forming processes. Survey shows that the role of numerical simulation and optimization to improve performance and quality of their products are still very limited. This paper describes the use of MARC finite element code in a single stage sheet metal forming simulation on square cup deep drawing. The MARC's results are validated with experimental results of benchmark problem square cup deep drawing in Numisheet '93. The paper also discusses the localized stress and strain values of the formed part
\end{abstract}

Keywords : square cup deep drawing, sheet metal forming, finite element, dies

\section{PENDAHULUAN}

Dunia industri saat ini dituntut untuk dapat membuat suatu produk secara efisien dan efektif. Satu cara yang mulai banyak dilakukan dunia industri adalah dengan memanfaatkan fasilitas perangkat lunak, namun hal ini belum dikembangkan secara maksimal bagi industri otomobil maupun karoseri. Sebenarnya penggunaan software sangat diperlukan terutama untuk desain bahkan hingga keperluan analisis atau yang lebih dikenal dengan finite elements analysis (FEA/FEM).

Menyangkut proses manufaktur di industri otomobil atau karoseri, sebagai contoh pada proses penempaan (stamping process) untuk membuat bodi mobil dari pelat yang dibentuk. Proses desain mulai dari merancang komponen yang diinginkan, membuat cetakan (dies) dan proses stamping, penggunaan FEA/FEM belum digunakan secara maksimal. Menurut Fallbohmer (1996) perusahaan otomobil di negara-negara industri seperti halnya Amerika Serikat, Jerman dan Jepang sekitar $10 \%$ perusahaan menggunakan FEA/FEM dalam desain dies dan selebihnya masih mengandalkan pengalaman dan handbooks.

Berkenaan dengan hal ini, selanjutnya akan dikaji tentang analisis square cup deep drawing dengan software MARC K7.3. Untuk melengkapi pengetahuan tentang proses penempaan, penulis melakukan survei di PT. Mekar Armada Jaya Magelang (New Armada) pada divisi teknik bagian stamping plan.

\section{PROGRAM MARC K7.3}

Pertama dipelajari sejak tahun 1965 di Universitas Brown, yaitu mengembangkan analisis struktur dengan komputasi untuk keperluan NASA. Tahap selanjutnya lahir MARC Analysis Research Corporation yang didirikan pada tahun 1971, dan tahun 1972 mengeluarkan program pertama mereka yaitu MARC General purpose For FEA Non Linier Software. Sekarang MARC Corporation bergabung dengan MSC Software pada tahun 1999. 


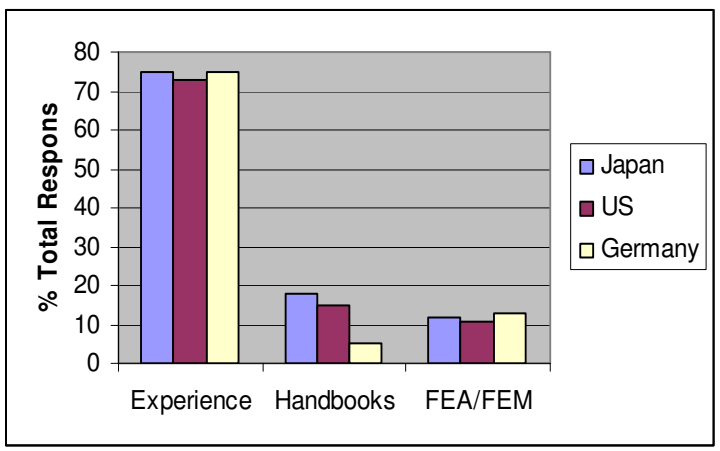

Gambar 1. Peranan FEA/FEM dalam die design (Fallbohmer, 1996)

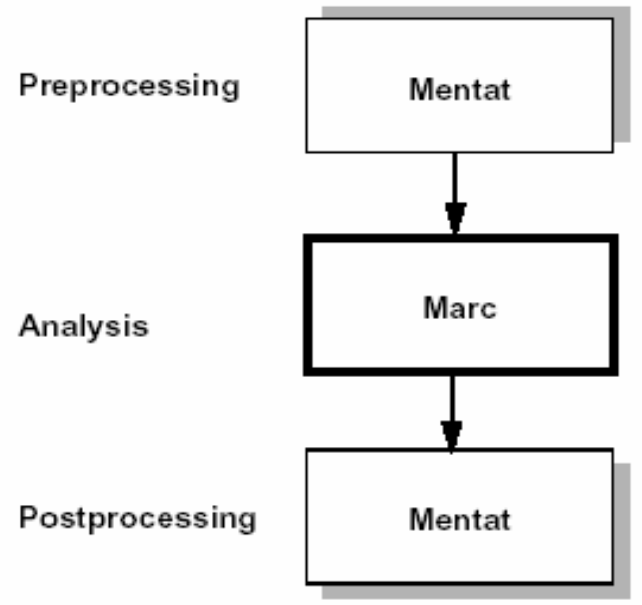

Gambar 2. Sistem Struktur Program MARC

MARC K7.3 dan Mentat 3.3 yang digunakan dalam keperluan ini adalah keluaran tahun 1997. Untuk mengenal lebih mendalam mengenai program dan cara kerjanya, dapat dijelaskan dengan diagram pada gambar 2.

Gambar 2 menunjukkan hubungan antara MARC dan Mentat yang menjadi sebuah program yang interaktif. Sistem kerjanya Mentat sebagai graphical user interface yang berfungsi untuk membuat geometri, menentukan kondisi batas, beban dari struktur yang kita tentukan dan menampilkan hasil analisis dan MARC untuk menganalisis informasi dari Mentat yang diinformasikan dalam fungsi elemen hingga.

MARC dan Mentat adalah program yang terintegrasi dan berbasis elemen hingga yang dapat membantu menyelesaikan masalah-masalah teknik dan analisis seperti linear elastic, geometrically nonlinear, physically nonlinear, contact, dynamic, dan heat transfer and thermal analysis.

Sheet metal forming adalah sebuah proses yang bertujuan agar pelat atau material mengalami deformasi plastis sehingga terbentuk komponen dari desain yang diinginkan. Penggunaan sheet metal forming menjadi teknik pembentukan yang efektif karena dapat menggantikan proses permesinan dan pengelasan. Komponen yang dihasilkan dari sheet metal forming dari bentuk yang sangat sederhana sampai bentuk-bentuk yang rumit dan kecil seperti yang diperlukan industri elektronik dan menghasilkan komponen besar seperti bodi mobil pada industri otomotif. 


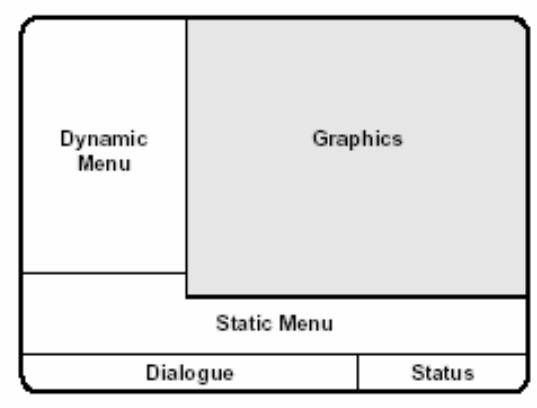

Gambar 3. Tampilan dasar dilayar komputer

Aplikasi sheet metal forming menjadi sangat penting di industri otomotif sejak komponen-komponen mobil dihasilkan dari proses pembentukan dengan penekanan (press forming processes) karena komponen yang dihasilkan lebih bagus dari proses pembentukan yang lain seperti halnya pengelasan, selain itu sangat praktis hanya menggunakan beberapa set peralatan cetakan (rigid tooling dies) dapat menghasilkan ribuan komponen dengan bentuk dan dimensi yang identik.

Bagian die (rigid tooling dies) yang umum dipakai yaitu punch merupakan die bagian atas yang berfungsi menekan pelat kebawah, lower die merupakan die bagian bawah dan blank holder adalah bagian yang dapat bergerak naik turun yang berfungsi sebagai pencekam pelat agar tetap pada posisi yang stabil.
Proses pengepresan pelat tergantung dari kompleksitas bentuk komponen yang dibuat, untuk bentuk sederhana hanya diperlukan satu tahap pembentukan (single stage metal forming) dan bentuk yang komplek tidak dapat dibuat dalam satu tahap, tetapi dengan beberapa tahap dan dioperasikan pada peralatan cetakan yang berbeda pula (multistage metal forming process)

\section{METODE ELEMEN HINGGA}

Metode elemen hingga banyak digunakan karena merupakan solusi numerik yang dapat memecahkan persoalan-persoalan mekanika dengan geometri maupun pembebanan yang kompleks.

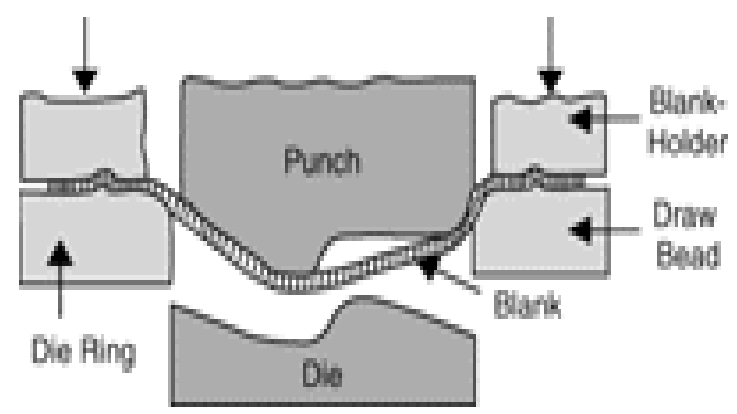

Gambar 4. Bagian-bagian die 


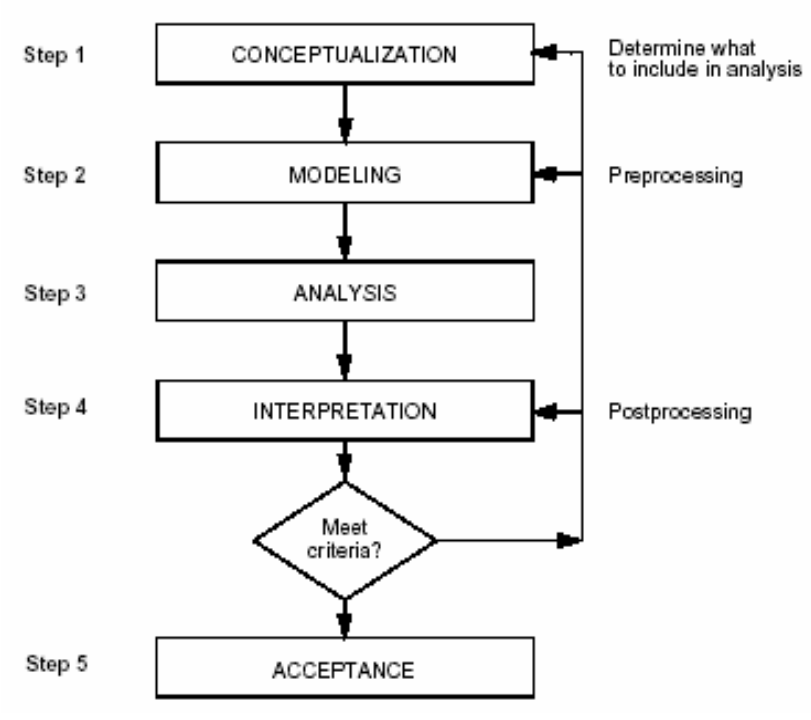

Gambar 5. Prosedur analisis elemen hingga dengan MARC.

Diagram alir gambar 5 dijelaskan langkah-langkah penyelesaian analisis elemen hingga secara komputasi mempergunakan program MARC.

Step 1 adalah tahap membuat konsep dasar, yaitu proses penentuan bentuk geometris suatu komponen atau part agar dapat memenuhi fungsi yang ditentukan.

Step 2 akan meneruskan informasi dari konsep dasar agar dapat diterjemahkan sebagai fungsi elemen hingga yang didalamnya menentukan node, elemen, kondisi batas (boundary conditions) dan beban yang bekerja.

Step 3 adalah langkah iterasi yang merupakan analisis berulang-ulang untuk mendapatkan hasil yang konvergen

Step 4 merupakan tahapan untuk mengevaluasi hasil dengan melihat deformasi, tegangan, regangan, temperatur dan lain-lain.

Step 5 adalah tahapan akhir untuk mengevaluasi apakah hasil analisis memenuhi kriteria dan dapat digunakan pertimbangan lebih lanjut.

Proses stamping dalam aplikasi software MARC dan Mentat termasuk dalam analisis kontak (contact analysis). Kontak di dalam MARC dan Mentat didefinisikan sebagai kelompok elemen atau geometri yang dapat melakukan penekanan baik dengan sendirinya atau dengan yang lain, yang di dalamnya terdapat benda deformable (distribusi tegangan dan temperatur), rigid (tidak ada distribusi tegangan, temperatur konstan) dan rigid allowing heat transfer (pengaruh temperatur saja).

\section{PROBLEM SQUARE DEEP DRAWING}

Di dalam melakukan riset, problem yang dijadikan kasus untuk dianalisis yaitu square deep drawing. Riset mengenai kasus serupa juga pernah dilakukan Makinouchi (1993) dan nantinya akan dijadikan pembanding apakah analisis yang dilakukan dengan mempergunakan software MARC K7.3 bisa diterima untuk aplikasi kasus-kasus lainnya. Dasar yang dipakai sebagai pijakan adalah konferensi di Isehara, Jepang tahun 1993, mengenai standar atau acuan terhadap penggunaan software untuk aplikasi simulasi sheet metal forming,

Asumsi penggunaan material dalam pemodelan adalah material anisotropic dengan data sebagai berikut : 
- Bahan : mild steel,

- Tebal : 0,78 mm,

- Luas plat : $150 \mathrm{~mm}$ x $150 \mathrm{~mm}$

\section{Drawing Simulations}

Langkah pertama blank holder bergerak turun menekan plat dengan gaya $4,9 \mathrm{kN}$ (untuk 1/4 model). Blank holder ini bekerja sampai proses selesai. Langkah ke dua, punch turun sejauh $40 \mathrm{~mm}$ dengan kecepatan variasi dari $0 \mathrm{~m} / \mathrm{s} \rightarrow 8 \mathrm{~m} / \mathrm{s} \rightarrow 0$ $\mathrm{m} / \mathrm{s}$.

\section{ANALISIS VALIDASI}

Dalam menganalisis masalah, material yang digunakan adalah material isotropic yang menganggap bahwa material mempunyai nilai yang sama pada sudut rolling direction, dalam hal ini diambil rata-rata $\left(\sigma=565.32\left(0.007117+\varepsilon_{\mathrm{p}}\right)^{0.2589}\right.$, yield stress $173.1 \mathrm{~N} / \mathrm{mm}^{2}$ dan tensile stress $311.4 \mathrm{~N} / \mathrm{mm}^{2}$ ).

Dalam validasi ini forming processes merupakan proses quasistatic atau dianggap proses yang statis yaitu mengharap tidak adanya kejutan yang mengakibatkan impak pada material. Untuk menghindari hal tersebut laju punch bergerak dari kecepatan $0 \mathrm{~m} / \mathrm{s}$ kemudian kecepatan terus naik dan berhenti pada
- Modulus Young E = 206 Gpa, poisson's ratio $v=0.3$

- Koesisien gesek : 0.144

kecepatan $0 \mathrm{~m} / \mathrm{s}$, (gambar 4.11), untuk blank holder gaya yang dikenakan tidak langsung sebesar 4,9 $\mathrm{kN}$ melainkan dari 0 $\mathrm{kN}$ kemudian naik hingga gaya menjadi $4,9 \mathrm{kN}$

Validasi ini berguna untuk mengecek displacement (D) pelat setelah terbentuk oleh turunnya punch sejauh $15 \mathrm{~mm}$ dan 40 $\mathrm{mm}$.

Dalam analisis model dibuat $1 / 4$ dengan punch, die, dan blank holder dianggap rigid surface (tidak ada distribusi tegangan dan temperatur) dan blank(pelat) sebagai elemen yang deformable. Plat dibagi menjadi 900 elemen quad (4) dengan 4 node (MARC element 75). Pemodelan dapat diilustrasikan gambar 6.

Dari hasil analisis dan simulasi dapat dilihat pada tabel 2. Hasil menunjukkan bahwa displacement DX, DZ dan DD angka-angkanya masih dalam range eksperimen(Makinouchi,1993). Nilai DX dan DZ menunjukkan angka yang hampir sama, hal ini disebabkan dari penggunaan material isotropik.

Tabel 1. Formulasi True Stress

\begin{tabular}{cc}
\hline $\begin{array}{c}\text { Rolling } \\
\text { Direction }\end{array}$ & $\begin{array}{c}\text { True Stress Rules } \\
\left(\mathrm{N} / \mathrm{mm}^{2}\right)\end{array}$ \\
\hline $0^{\circ}$ & $\sigma=567.29\left(0.007127+\varepsilon_{\mathrm{p}}\right)^{0.2637}$ \\
$45^{0}$ & $\sigma=568.00\left(0.007450+\varepsilon_{\mathrm{p}}\right)^{0.2589}$ \\
$90^{0}$ & $\sigma=553.38\left(0.006444+\varepsilon_{\mathrm{p}}\right)^{0.2543}$ \\
Rata-rata & $\sigma=565.32\left(0.007117+\varepsilon_{\mathrm{p}}\right)^{0.2589}$ \\
\hline
\end{tabular}




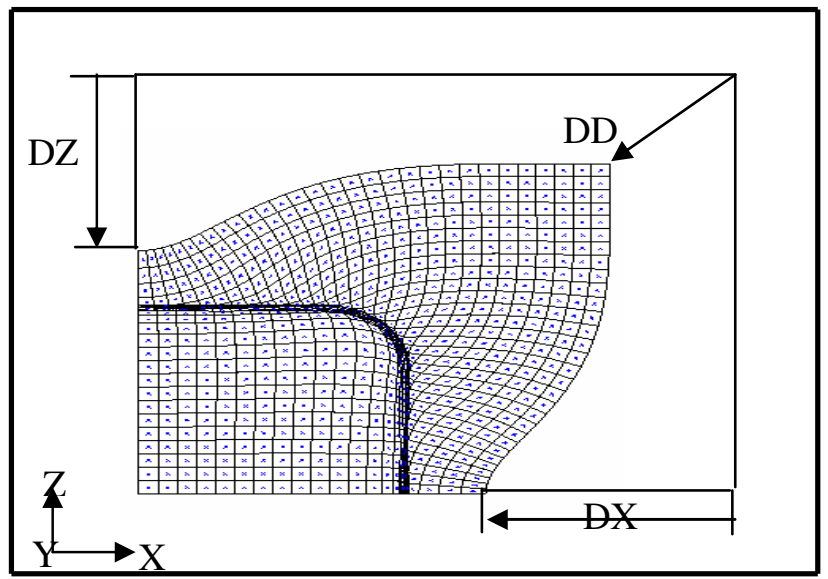

Gambar 6. Posisi displacement pelat

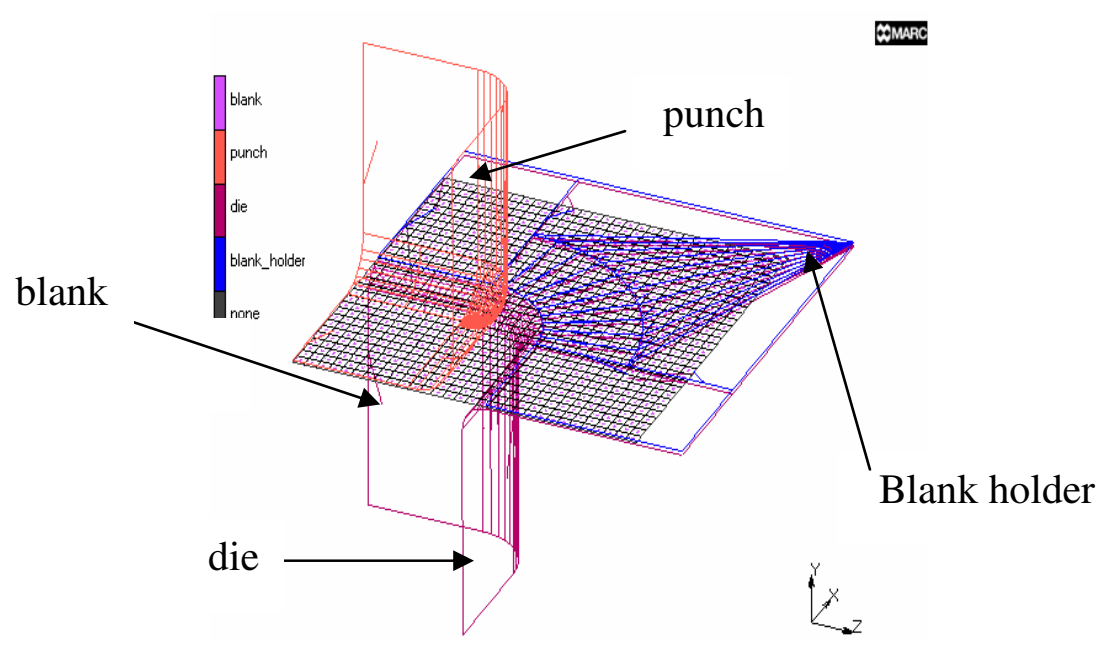

Gambar 7. Model square cup deep drawing saat punch belum bergerak ke bawah

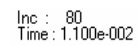
MMARC

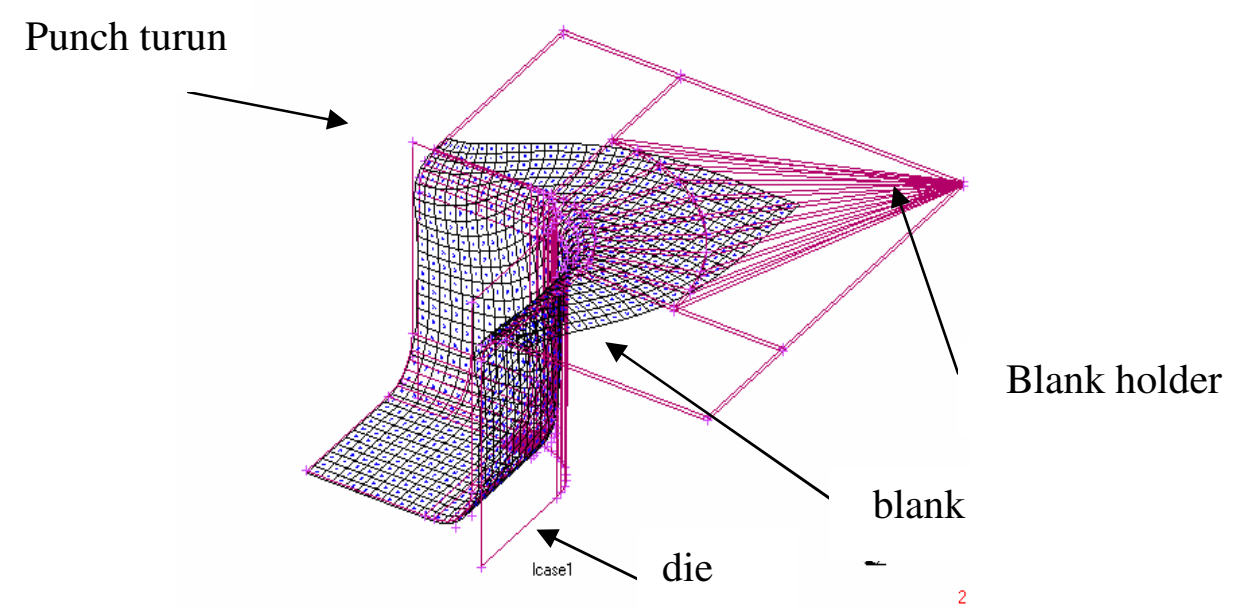

Gambar 8. Model square cup deep drawing dalam MARC saat punch bergerak ke bawah 
Tabel 2. Hasil validasi MARC dengan hasil eksperimen Numisheet '93

\begin{tabular}{lcccccc}
\hline Punch travel & \multicolumn{3}{c}{$15 \mathrm{~mm}$} & \multicolumn{3}{c}{$40 \mathrm{~mm}$} \\
\hline Displacement & DX (mm) & DZ (mm) & DD (mm) & DX (mm) & DZ (mm) & DD (mm) \\
$\begin{array}{l}\text { Makinouchi,1993 } \\
\text { (eksperimen) }\end{array}$ & $5.50-7.00$ & $5.50-7.10$ & $2.50-3.90$ & $27.75-29.60$ & $26.75-9.58$ & $14.60-6.31$ \\
Simulasi MARC & 6.93 & 6.96 & 3.74 & 28.55 & 29.38 & 16.0 \\
\hline
\end{tabular}

\section{SIMULASI}
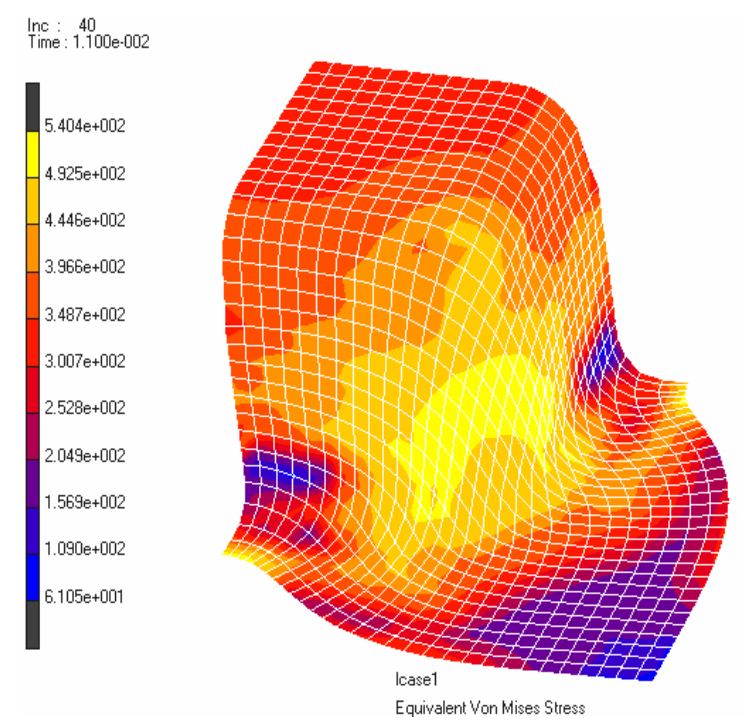

Gambar 9. Distribusi tegangan pada kedalaman punch $40 \mathrm{~mm}$
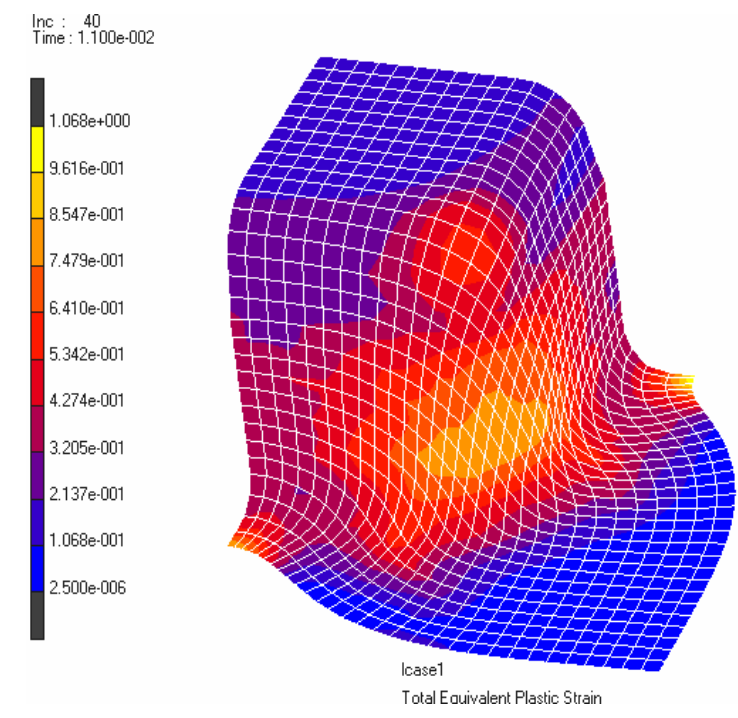

Gambar 10. Distribusi regangan pada kedalam punch $40 \mathrm{~mm}$. 


\section{KESIMPULAN}

Dari hasil analisis validasi dapat dilihat bahwa program MARC K7.3 bisa dipergunakan dalam aplikasi sheet metal forming simulation.

Kualitas pembentukan dalam proses produksi bisa diprediksi dengan simulasi mempergunakan software MARC K7.3 dan bahkan bisa diketahui distribusi tegangan regangan, kondisi ketebalan pelat yang bermanfaat untuk proses analisis selanjutnya. Melalui uji simulasi memakai software akan mampu menggantikan uji materil yang sifatnya merusak suatu produk

\section{DAFTAR PUSTAKA}

Fallbohmer P., Altan T., Tonshoff H.-K., Nakagawa T., 1996, Survey of The Die And Mold Manufacturing Industry-Presices in Germany, Japan, and The United States, Journal of Materials Processing Technology.

Makinouchi A., Nakamichi E., Onate E., Wagoner R.H., 1993, NUMISHEET '93, Numerical Simulation of 3-D Sheet Metal Forming Processes-Verification of Simulation with Experiment, Proceeding of The 2nd International Conference, Isehera, Japan.

Umehera, 1990, Technologies for the More Precise Press Forming: An Explicit to Implicit Sequential Solution Procedure, Finite Element in Analysis Design, V.33, pp. 29-42. 